\title{
Siderophore Production by Bacillus megaterium: Effect of Growth Phase and Cultural Conditions
}

\author{
Sofia Santos • Isabel F. F. Neto • Manuela D. Machado • \\ Helena M. V. M. Soares $•$ Eduardo V. Soares
}

Received: 8 July 2013 / Accepted: 27 September 2013 /

Published online: 8 October 2013

(C) Springer Science+Business Media New York 2013

\begin{abstract}
Siderophore production by Bacillus megaterium was detected, in an iron-deficient culture medium, during the exponential growth phase, prior to the sporulation, in the presence of glucose; these results suggested that the onset of siderophore production did not require glucose depletion and was not related with the sporulation. The siderophore production by $B$. megaterium was affected by the carbon source used. The growth on glycerol promoted the very high siderophore production $\left(1,182 \mu \mathrm{mol} \mathrm{g}^{-1}\right.$ dry weight biomass); the opposite effect was observed in the presence of mannose $\left(251 \mu \mathrm{mol} \mathrm{g}^{-1}\right.$ dry weight biomass). The growth in the presence of fructose, galactose, glucose, lactose, maltose or sucrose, originated similar concentrations of siderophore (546-842 $\mathrm{mmol} \mathrm{g}^{-1}$ dry weight biomass). Aeration had a positive effect on the production of siderophore. Incubation of $B$. megaterium under static conditions delayed and reduced the growth and the production of siderophore, compared with the incubation in stirred conditions.
\end{abstract}

Keywords Bacillus megaterium - Carbon source - Environmental-friendly chelating agents · Iron chelator $\cdot$ Siderophore production

\section{Introduction}

Chelating agents of the type aminopolycarboxylates (APCAs), such as ethylenediaminetetracetic acid (EDTA) and diethylenetriaminepentacetic acid (DTPA), have the capacity to form stable

S. Santos $\cdot$ M. D. Machado $\cdot$ E. V. Soares $(\bowtie)$

Bioengineering Laboratory-CIETI, Chemical Engineering Department, ISEP-School of Engineering of Polytechnic Institute of Porto, Rua Dr António Bernardino de Almeida, 431, 4200-072 Porto, Portugal e-mail: evs@isep.ipp.pt

I. F. F. Neto $\cdot H$. M. V. M. Soares $(\bowtie)$

REQUIMTE-Department of Chemical Engineering, Faculty of Engineering, University of Porto, Rua Dr Roberto Frias, s/n, 4200-465 Porto, Portugal

e-mail: hsoares@fe.up.pt

M. D. Machado $\cdot$ E. V. Soares

IBB-Institute for Biotechnology and Bioengineering, Centre for Biological Engineering, Universidade do Minho, Campus de Gualtar, 4710-057 Braga, Portugal 
complexes with di- and trivalent metal ions. Due to this ability, these compounds are widely used in a variety of domestic products and industrial applications and are produced in huge quantities. It is estimated that world consumption of EDTA and DTPA is about 200,000 t per year [1]. APCAs are worldwide used in medicine, agriculture, detergents and healthcare products, environment, and industry (namely pulp and paper industry) [2]. These compounds are nonbiodegradable. High concentrations may lead to the remobilization of metals from sediments and aquifers, consequently posing a risk to groundwater and drinking water [3]. By this reason, the use of nonbiodegradable chelating agents is becoming a matter of great concern. Alternating compounds with complex forming comparable to those APCAs and showing better biodegradability are needed to be introduced.

APCAs are also naturally occurring compounds. This is the case of ethylenediaminedisuccinate (EDDS), produced by Amycolatopsis orientalis, and rhizobactin, produced by Rhizobium meliloti; the last chelating agent is considered a siderophore [4]. Siderophores are low molecular weight iron-binding compounds, produced by plants and microorganisms, in response to the low levels of iron available in the environment [5]. These molecules play an important role in the solubilization of iron from minerals [6]. Although siderophores displayed highest affinity for ferric iron, these molecules can also form strong complexes with other metals [7, 8] and are better biodegradable than most synthetic APCAs [8]; this fact constitutes a considerable advantage. In fact, the analysis of the variation of the conditional stability constants in function of $\mathrm{pH}$ between $\mathrm{Fe}^{3+}$ and aerobactin (this is a dihydroxamate chelator with a citric acid backbone, which structure is similar to schizokinen) [5], EDTA or EDDS reveals that, even though the affinity between $\mathrm{Fe}^{3+}$ and aerobactin is slightly lower (for $\mathrm{pH}<7$ ) than for EDTA, aerobactin is an effective chelating agent in a wide $\mathrm{pH}$ range with an affinity comparable or better than EDDS [9]. Additionally, the biodegradation of hydroxamate siderophores, such as ferrichrome A [10] and desferrioxamine B $[11,12]$, has been described. Due to all these reasons, these compounds can potentially substitute EDTA for industrial/commercial use.

Siderophores can be used in agriculture [13] and medicine [14, 15]. For example, the siderophore desferrioxamine B, produced by Streptomyces pilosus, has medical application, as a chelating agent. This compound is a hydroxamate-based siderophore, which can be used to remove excess of iron from the human body [16]; this compound is marketed as the mesylate salt, under the name of Desferal [14]. Siderophores can also be used for selective delivery of antibiotics in antibiotic resistant bacteria. The ability of siderophores to transport iron is used to carry drugs into cells by preparation of conjugates between siderophores and antimicrobial agents. It uses siderophores as mediators to facilitate the cellular uptake of antibiotics. Albomycins, ferrimycins, salmycins, and microcins are examples of siderophores used for this type of application [15]. Additionally, it was demonstrated that siderophores have the potential to play a role in the $\mathrm{Fe}$ nutrition of plants. Thus, the application of Fe-rhizoferrin complex (rhizoferrin is a fungal siderophore produced by Rhizopus arrhizus), as an iron source for various type of plants (tomato, cucumber, barley, and corn), was found to be an efficient carrier of iron [17].

Bacillus megaterium has the ability to produce a siderophore [6]. This compound was originally isolated as a factor associated with the initiation of cell division and cell growth and was called schizokinen [18]. Later, it was found that under iron-deficient conditions, $B$. megaterium produces and excretes siderophore that bind ferric iron and transport it into the cell $[19,20]$. The iron is intracellularly released from the siderophore, by an enzymatic reduction [21]; the siderophore is recycled and released from the cell in a "shuttle mechanism" [19]. Schizokinen is a dihydroxamate siderophore, constituted by a citric acid residue symmetrically substituted with 1 -amino-3-( $N$-hydroxyl- $N$-acetyl)-aminopropane $[22,23]$.

In Gram-negative bacteria, siderophore biosynthesis is controlled by repressor proteins, being ferric uptake regulation (Fur) the most important. Fur-like proteins have also been 
found in many Gram-positive organisms. Fur protein is an iron-dependent repressor, acts at the transcriptional level and binds to specific DNA regulatory sequences, in response to iron availability [24]. Schizokinen production by $B$. megaterium is repressed by the presence of $0.04 \mathrm{mg} \mathrm{l}^{-1}$ of iron [25]. High aluminum concentration increased formation of siderophore in iron-limited cultures; however, the presence of aluminum did not stimulate siderophore production in iron replete conditions [25]. The exposition of $B$. megaterium to chromium and zinc also enhanced siderophore production [26, 27]. Schizokinen is also produced by the bacterium Rhizobium leguminosarum [28], the cyanobacteria Anabaena sp. [29] and Anabaena flos-aquae [30], in response to iron-limited conditions.

As far as we know, besides the effects of metals, no information is available in the literature about the physiology and the culture conditions on the siderophore production by B. megaterium or by other microorganisms able to produce schizokinen. In the present work, the influence of growth phase, cultural conditions (carbon source, arginine concentration, and the influence of agitation) on the production of siderophore by B. megaterium, in irondeficient conditions, was investigated.

\section{Materials and Methods}

Strain, Media, and Culture Conditions

In this work, B. megaterium American Type Culture Collection (ATCC) 19213 was used. The original strain was obtained from the ATCC, USA. The microorganism was maintained in nutrient agar slants, at $4{ }^{\circ} \mathrm{C}$. B. megaterium was grown in an iron-deficient culture medium described by $\mathrm{Hu}$ and Boyer [25]. The medium, contained per liter: $1.0 \mathrm{~g} \mathrm{~K}_{2} \mathrm{SO}_{4}$, $3.0 \mathrm{~g} \mathrm{Na}_{2} \mathrm{HPO}_{4}, 3.0 \mathrm{~g} \mathrm{CH}_{3} \mathrm{COONH}_{4}, 20$ g glucose (unless mentioned otherwise), $800 \mathrm{mg}$ $\mathrm{MgSO}_{4} .7 \mathrm{H}_{2} \mathrm{O}, 8.6 \mathrm{mg} \mathrm{ZnSO}_{4} \cdot 7 \mathrm{H}_{2} \mathrm{O}, 0.113 \mathrm{mg} \mathrm{MnSO}_{4} \cdot \mathrm{H}_{2} \mathrm{O}$, and $1.5 \mathrm{~g}$ (unless stated otherwise) arginine hydrochloride. The $\mathrm{pH}$ value of the culture medium was adjusted to $7.0 \pm 0.1$. Iron-replete medium contained $29 \mathrm{mg} \mathrm{FeCl}_{3}$ per liter. Iron contamination, due to glassware, on iron-deficient cultures was avoided by soaking all glassware in $10 \%$ nitric acid overnight and subsequent washing with deionized water.

The starter cultures were prepared in $20 \mathrm{ml}$ of iron-replete medium in $100 \mathrm{ml}$ Erlenmeyer flasks. Cells were incubated at $37^{\circ} \mathrm{C}$ for $24 \mathrm{~h}$. Subsequently, cells were inoculated in $20 \mathrm{ml}$ of iron-deficient medium in $100 \mathrm{ml}$ Erlenmeyer flasks and grown for $8 \mathrm{~h}\left(\mathrm{OD}_{600} \sim 0.5\right)$ at $25^{\circ} \mathrm{C}$, on an orbital shaker, at $150 \mathrm{rpm}$. In order to limit the carryover of iron from the starter culture and to obtain cells in exponential phase of growth, cells were then inoculated in $20 \mathrm{ml}$ of iron-deficient medium in $100 \mathrm{ml}$ Erlenmeyer flasks and grown overnight $\left(\mathrm{OD}_{600} \sim 1.5\right)$, at $25^{\circ} \mathrm{C}$, on an orbital shaker, at $150 \mathrm{rpm}$. Cultures were prepared with an initial $\mathrm{OD}_{600} \sim 0.02$ (except for growth curves, initial $\mathrm{OD}_{600} \sim 0.1$ ) by inoculating 40 or $400 \mathrm{ml}$ of iron-deficient medium in $100 \mathrm{ml}$ or 1-1 Erlenmeyer flasks, respectively, with cells in exponential phase grown overnight. Then, cells were grown at $25^{\circ} \mathrm{C}$, on an orbital shaker, at $150 \mathrm{rpm}$.

The iron concentration in the overnight culture was below the detection limit $\left(36 \mu \mathrm{g} \mathrm{l}^{-1}\right)$ of the quantification method used (see below "Iron determination"). This result is in agreement with the expected theoretical concentration (20-34 $\left.\mathrm{g} \mathrm{I}^{-1}\right)$ calculated considering the initial growth in iron-replete medium and the subsequent growth in iron-deficient medium. Taking into account the dilution factor, the iron concentration in the cultures was below $0.7-3 \mu \mathrm{g} \mathrm{l}^{-1}$; these values are 13-57 times lesser than the iron concentration required to repress siderophore production. 
Growth was monitored spectrophotometrically (at $600 \mathrm{~nm}$ ) after appropriate dilution in deionized water. A calibration curve (absorbance versus dry weight biomass, expressed in grams per liter) was previously made.

For the determination of the siderophore production and the glucose concentration in culture medium, samples were taken at defined intervals of time, indicated in the figures, and cells were pelleted by centrifugation $(4,000 g, 5 \mathrm{~min})$. The supernatant was subsequently filtered through a $0.45-\mu \mathrm{m}$ pore size filter, collected and immediately stored at $-20{ }^{\circ} \mathrm{C}$ until siderophore or sugar determination.

\section{Evaluation of Siderophore Production}

The siderophore production was determined by chrome azurol S (CAS) method [31]. This method was chosen due to the following reasons: (1) it has been widely described in the literature that B. megaterium ATCC 19213 produces schizokinen; (2) CAS method is a high sensitive and efficient method to detect iron [32] and allows quantifying siderophore production in an easy way. Briefly, the CAS method consisted on mixing $1.0 \mathrm{ml}$ of the filtrate (appropriately diluted in deionized water) with $1.0 \mathrm{ml}$ of CAS assay solution, prepared as described by Alexander and Zuberer [31]. The mixture was allowed to equilibrate for $5 \mathrm{~h}$ in the dark at room temperature. Subsequently, the absorbance at $630 \mathrm{~nm}$ was measured. Zero absorbance was performed with a mixture containing the same volume of CAS assay solution and $4 \mathrm{mmol} \mathrm{l}^{-1}$ desferrioxamine mesylate salt (desferal; Sigma-Aldrich). As reference, the volume of filtrate was replaced by deionized water. A standard calibration curve was carried out by plotting the ratio $\left(A / A_{\text {ref }}\right)$ as a function of desferal concentration; wherein, $\mathrm{A}$ is the absorbance at $630 \mathrm{~nm}$ of each standard solution and $A_{\text {ref }}$ is the absorbance at $630 \mathrm{~nm}$ of the reference. Siderophore production (in micromoles per liter) was expressed as micromoles per liter desferal equivalent. In the experiments on the effect of the carbon source and arginine concentration, siderophore production was normalized as micromoles per liter dry weight biomass; the normalization was carried out by dividing the concentration of siderophore (in micromoles per liter) by the biomass concentration (in grams per liter dry weight biomass).

\section{Iron Determination}

The iron concentration in culture medium was measured by atomic absorption spectroscopy with flame atomization using a Perkin Elmer AAnalyst 400 spectrometer (Norwalk, CT, USA).

\section{Glucose Determination}

The glucose concentration in culture medium was measured as total reducing sugars by $3,5-$ dinitrosalicylic acid method [33].

\section{Spores Observation}

At defined intervals of time, samples were taken and cells were fixed with $3.5 \%(v / v)$ formaldehyde, for $2 \mathrm{~h}$, at room temperature with occasional mixing. Then, cells suspensions, in $3.5 \%(v / v)$ formaldehyde, were placed during $24 \mathrm{~h}$ at $4{ }^{\circ} \mathrm{C}$. Cells were examined by phase-contrast microscopy. The images were acquired with a Leica DC 300F camera (Leica Microsystems, Heerbrugg, Switzerland) using N plan objectives and processed using Leica IM 50-Image manager software. 
Reproducibility of the Results

All experiments were repeated, independently, at least, two times. The data reported for siderophore concentrations are the mean \pm standard deviation (SD), presented with $95 \%$ confidence value of at least four determinations.

\section{Results}

Growth Phase, Siderophore Production, and Sporulation

With the objective to evaluate the effect of growth phase on the siderophore production by the Gram-positive bacterium B. megaterium, the microorganism, in exponential phase of growth, was inoculated in iron-deficient medium. The B. megaterium, grew exponential during $14 \mathrm{~h}$, with a duplication time of about $135 \mathrm{~min}$, and reached the stationary phase between 14 and $24 \mathrm{~h}$ (Fig. 1a).

The siderophore was detected, in the culture medium, after $10 \mathrm{~h}$ of growth (Fig. 1b). Although a large increase on the siderophore production occurred through the end of the exponential phase of growth (14-24 h), the production of siderophore continued to occur during the stationary phase $(24-56 \mathrm{~h})$. After $10 \mathrm{~h}$ of growth, the glucose concentration in the culture medium was $17 \mathrm{~g}^{-1}$ (data not shown), which means that the triggering of siderophore production, by the $B$. megaterium, occurred in the exponential phase of growth and did not require the glucose exhaustion.

Microscopic observation of the culture showed that endospores could not be detected up to $14 \mathrm{~h}$ of growth. Structures, which resemble endospores, were only observed after $24 \mathrm{~h}$; typical sporulating cells were observed after $32 \mathrm{~h}$, while mature spores were observed after $48 \mathrm{~h}$ of growth (Fig. 2). Since the presence of siderophore was detected after $10 \mathrm{~h}$ of growth and the endospores after $24 \mathrm{~h}$, these results strongly suggested that siderophore production was not correlated with the sporulation in B. megaterium.

\section{Effect of Carbon Source}

The evaluation of the effect of the carbon source on the siderophore production had the aim of selecting the carbon source that induce the higher siderophore production in submerged cultures and/or is easier and economical to be obtained. Thus, the following carbon sources were tested: glycerol, monosaccharides (fructose, galactose, glucose, and mannose) and disaccharides (lactose, maltose, and sucrose). The production of siderophore was evaluated after $48 \mathrm{~h}$ of growth, when the strain was in the stationary phase, independently of the carbon source tested. As the biomass production varied with the carbon source under evaluation, the siderophore production, after $48 \mathrm{~h}$ of growth, was normalized as micromoles per gram dry weight biomass for each carbon source.

The growth of the bacteria in a culture medium with $2 \%(v / v)$ glycerol induced the higher siderophore production $\left(1,182 \pm 115 \mu \mathrm{mol} \mathrm{g}{ }^{-1}\right.$ dry weight biomass); conversely, the growth in the presence of $2 \%(w / v)$ of mannose originated the lesser siderophore production $\left(251 \pm 21 \mu \mathrm{mol} \mathrm{g}{ }^{-1}\right.$ dry weight biomass). Similar siderophore production was observed with $2 \%(w / v)$ of fructose, galactose, glucose, lactose, maltose, and sucrose $\left(546-842 \mu \mathrm{mol} \mathrm{g}^{-1}\right.$ dry weight biomass; Fig. 3). 

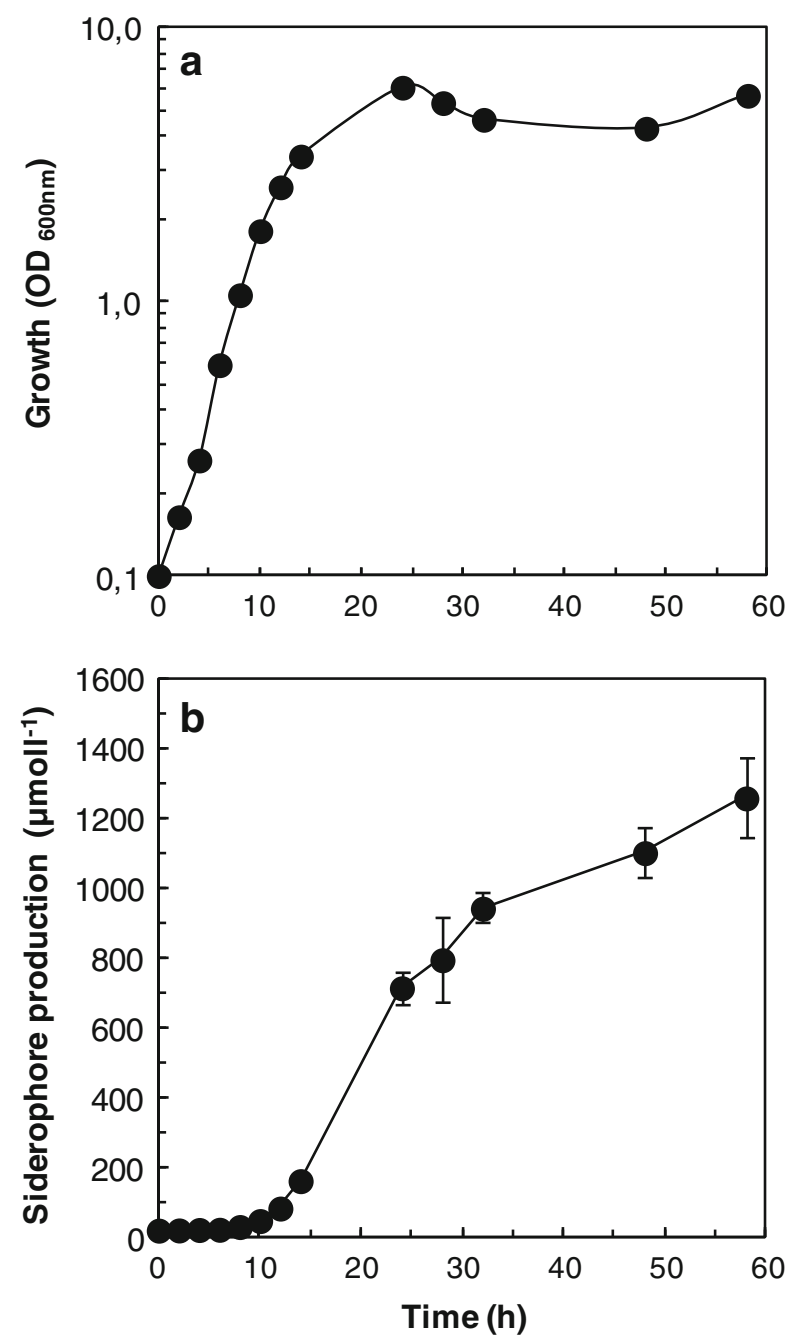

Fig. 1 Evolution of growth and siderophore production by the bacteria B. megaterium. The bacterium, in exponential phase of growth, was inoculated in iron-deficient medium and incubated at $25{ }^{\circ} \mathrm{C}$ and $150 \mathrm{rpm}$. Growth (a) and siderophore production (b). This is a typical example of an experiment performed two times; each point represents the mean of three (growth) or four determinations (siderophore production). Standard deviations are presented with $95 \%$ confidence limits (vertical error bars); where no error bars are shown, they are within the points

\section{Influence of Arginine Concentration}

It was described in the literature that the presence of arginine stimulated the siderophore production [23]. However, no data are available regarding the relationship between the arginine concentration and the level of stimulation of siderophore production. With the purpose to evaluate the stimulatory effect of arginine in the siderophore production by B. megaterium, different culture media were prepared containing two $\left(3.0 \mathrm{~g} \mathrm{l}^{-1}\right)$ and three $\left(4.5 \mathrm{~g} \mathrm{l}^{-1}\right)$ times more the concentration of arginine usually presented in the 


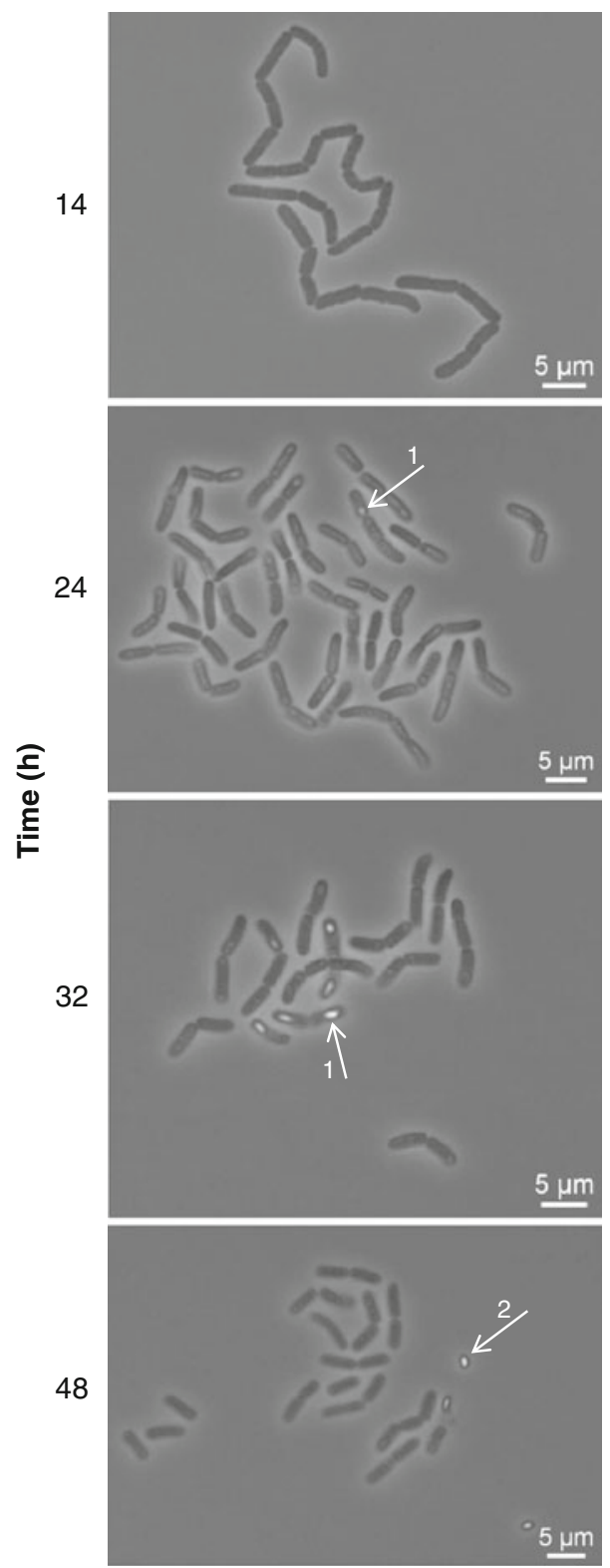

Fig. 2 Visualization of sporulation during the growth of B. megaterium in iron-deficient medium. Phase contrast micrographs of the cells grown in iron-deficient medium reported in Fig. 1. Arrows 1 sporulating cell; arrow 2 mature spore

medium $\left(1.5 \mathrm{~g} \mathrm{l}^{-1}\right)$. Similar values of siderophore were observed: $785 \pm 166,781 \pm 121$, and $841 \pm 91 \mu \mathrm{mol} \mathrm{g}^{-1}$ dry weight biomass for $1.5,3.0$, and $4.5 \mathrm{~g} \mathrm{l}^{-1}$ arginine, respectively. These results showed that the increase of arginine concentration did not stimulate the siderophore production by B. megaterium. 


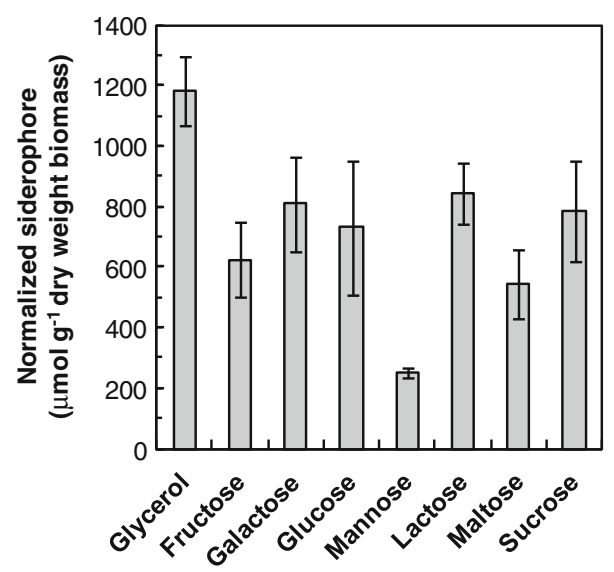

Fig. 3 Influence of carbon source on the siderophore production by B. megaterium. For each carbon source, the value of the siderophore production, after $48 \mathrm{~h}$ of growth, was normalized as micromoles per liter per gram dry weight biomass. Each bar represents the mean of two independent experiments; in each independent experiment, siderophore concentration was determined in quadruplicate. Standard deviations are presented with $95 \%$ confidence limits (vertical error bars)

\section{Influence of Agitation}

The effect of the absence of agitation on the growth and production of the siderophore by the $B$. megaterium was evaluated. The incubation of the bacterium in iron-deficient medium, in static conditions, resulted in a slow growth (Fig. 4a) and in a reduction of the siderophore production (Fig. 4b), compared with the growth in the same conditions (culture medium and temperature) but with an agitation of $150 \mathrm{rpm}$ (Fig. 1a,b). The siderophore production was not repressed in the absence of agitation. However, the amount of siderophore present in the culture medium after 20 days $\left(223 \pm 3 \mu \mathrm{mol}^{-1}\right)$ was about $20 \%$ of the siderophore produced after $48 \mathrm{~h}$ of growth $\left(1,103 \pm 69 \mu \mathrm{mol} \mathrm{l}{ }^{-1}\right)$ with an agitation of $150 \mathrm{rpm}$. The normalization of the siderophore production, taken into account the growth, also showed a marked reduction under static conditions. The values of the amount of normalized siderophore after 20 days, in static conditions $\left(401 \pm 5 \mu \mathrm{mol} \mathrm{l}^{-1}\right)$, were about $60 \%$ of the siderophore produced after $48 \mathrm{~h}$, in agitated conditions $\left(673 \pm 26 \mu \mathrm{mol} \mathrm{^{-1 }}\right)$. These results highlight the importance of the agitation, and consequently, the presence of oxygen in the stimulation of growth and siderophore production by the bacteria $B$. megaterium.

\section{Discussion}

Microorganisms are able to produce natural APCAs, which are implicated in the metal uptake by these organisms [4]. Natural APCAs, such as the case of siderophores, can be a promising alternative to synthetics ones because they are environmental friendly compounds [8] with the ability to complex different metals [34].

The biotechnological production of siderophores, in liquid cultures, constitutes a feasible option due to the possibility of controlling the fermentation parameters that influence the biosynthesis of these compounds [35]. B. megaterium has been industrially used for more than 50 years in the production of enzymes, vitamins, fungicidal toxins, or a viral inhibitor active on human immunodeficiency virus [36]; this microorganism is also able to produce a 

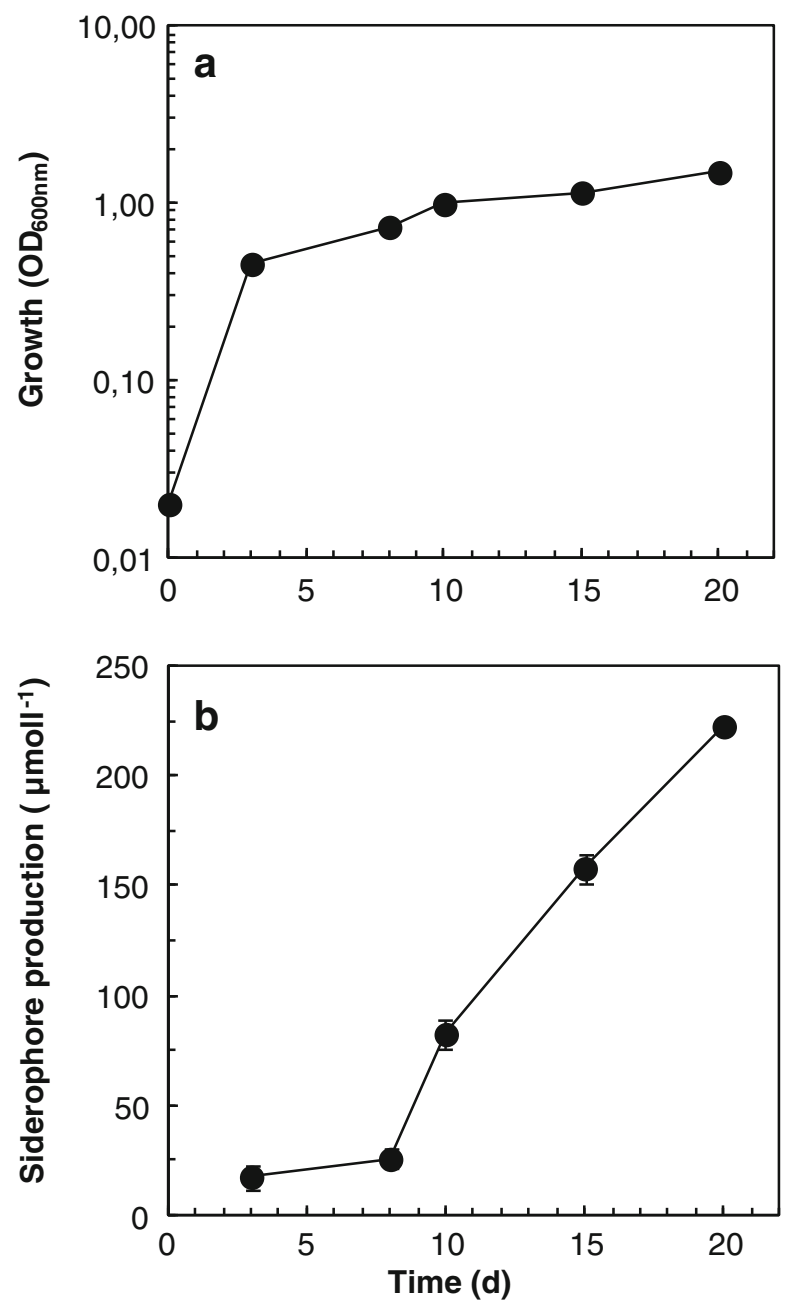

Fig. 4 Growth and siderophore production by B. megaterium incubated in static conditions. Growth (a); siderophore production (b). The bacterium, in exponential phase of growth, was inoculated in iron-deficient medium and was incubated, in static conditions, at $25^{\circ} \mathrm{C}$. This is a typical example of an experiment performed two times; each point represents the mean of three (growth) or four determinations (siderophore production). Standard deviations are presented with $95 \%$ confidence limits (vertical error bars); where no error bars are shown, they are within the points

siderophore. In the present work, the influence of $B$. megaterium physiology and the impact of culture conditions on the siderophore production were studied. These information are of fundamental importance on the design of the siderophore production processes.

Bacteria of the genus Bacillus have the ability to produce antibiotics, such as bacitracin, as secondary metabolites [37]. These compounds are never produced by rapidly growing bacilli under catabolic repression; the biosynthesis of these compounds are associated with spore formation, after relief from metabolic repression (i.e., under limited nutrients conditions) [37-40]. In the present work, the production of siderophore, by B. megaterium, in iron-deficient medium, was detected in the middle of exponential phase of growth, prior of 
the appearance of sporulation (Figs. 1 and 2). These results suggest that siderophore production, by $B$. megaterium, is not associated with spore formation. On the other hand, exponential growth and siderophore production occurred simultaneously (Fig. 1), in the presence of glucose, which suggests that the onset of siderophore production was not affected by the availability of the carbon source. A similar observation has been reported for rhizoferrin production by Cunninghamella elegans [41]. A different behavior seems to occur with $B$. anthracis. In recent years, it was described that B. anthracis secretes temporally two siderophores in low-iron medium: petrobactin, during outgrowth from spores and bacillibactin produced several hours later in the growth cycle [42].

Siderophore production by Pseudomonas sp. [43] and Pseudomonas fluorescens [44] is influenced by the nature of the carbon source. Carbon catabolism is of great practical importance for fermentation, once the price and availability of the carbon source is a critical issue on the development of an economical fermentation process [35]. B. megaterium is a very versatile microorganism since it is able to use more than 62 carbon sources, including different monoand disaccharides as single sources of carbon and energy, in simple media $[36,45]$. In order to maximize the siderophore production and/or reduce the costs associated with its production, different carbon sources were tested. It was found that the growing of $B$. megaterium in a culture medium containing glycerol enhanced siderophore production (Fig. 3). Similarly, Gupta et al. [46] described an inducible effect of glycerol on lipase production by Bacillus sp. Glycerol can be an alternative carbon source for industrial production of the siderophore by B. megaterium; besides, the stimulation of the siderophore production, glycerol can be obtained as a by-product of biodiesel production. In fact, the rapid expanding of biodiesel industry originated a large increase in the worldwide availability of glycerol. Currently, the glycerol market is saturated. As a consequence, the glycerol prices continue to decline, falling down to zero and even negative values; as a consequence, glycerol producers are forced to pay for withdraw it from their plants [47]. Due to this reason, it becomes important to seek alternative processes for glycerol consumption such as the case of its conversion to value-added compounds. The biotechnological production of siderophores by fermentation, using glycerol as carbon source, can be an interesting alternative.

Another possibility can be the use of lactose as carbon source. This disaccharide induced a similar production of siderophore than sucrose or glucose (Fig. 3). Lactose can be obtained, in large amounts, as a by-product of dairy industries. Whey is obtained during cheese production and is usually processed to whey powder or lactose. Due to the presence of lactose (the most abundant component of whey, 4.5-5\%,w/v), whey can be used as a base of culture medium formulation to obtain valuable products by fermentation such as single cell protein, organic acids, vitamins, enzymes, bioethanol [48], or a siderophore.

Amino acids supplement (glycine, aspartic acid, or glutamic acid) to culture medium increased siderophore production by fungi [43]. Mullis et al. [23] suggested that arginine stimulated the siderophore production by $B$. megaterium. In the present work, the increase of arginine concentration (two or three times the value usually present in the culture medium) did not stimulate the siderophore production by B. megaterium. As the increase of arginine concentration (in the absence of modification of carbon source concentration) reduced the carbon/nitrogen ratio, this result also suggests that the modification of carbon/nitrogen ratio did not affect the siderophore production.

Most of the bioprocesses are based on reactors that operate in a batch mode. In the case of stirring tank reactors, the aerobic conditions are provided due to the aeration (by the introduction of air through a sparger) and the agitation (ensured by a central shaft that supports one or more impellers) [49]. In an industrial point of view, the operation of fermentation under static conditions reduces the costs of the overall process due to the reduction of costs of equipment 
and energy demand associated with the aeration and agitation. However, as it is shown in this work, the incubation of $B$. megaterium in static conditions slowed the growth. Although the absence of agitation did not prevent the siderophore production, it strongly decreased its production (Fig. 4). These results strongly suggested the involvement of aerobic metabolism in the production of the siderophore. Therefore, the fermentative process for siderophore production, by $B$. megaterium, should be carried out in aerobic conditions.

In conclusion, the siderophore production by $B$. megaterium in iron-deficient medium detected in the exponential phase of growth seems not to be affected by the glucose availability and was not related with the onset of endospores formation. The carbon source affected the siderophore production by B. megaterium. Among the carbon sources tested, the growth on glycerol promoted the highest siderophore production. The increase of arginine concentration in the culture medium did not enhance the siderophore production. The agitation had a positive effect on the growing of $B$. megaterium and siderophore production. To our knowledge, this is the first work that describes the physiological response of $B$. megaterium in terms of siderophore production.

Acknowledgments The authors thank Porto University/Totta Bank for their financial support through the project "Microbiological production of chelating agents" (Ref: 180). The authors also thank the Fundação para a Ciência e a Tecnologia (FCT) through the Portuguese Government for their financial support of this work through the grants Strategic project-LA23/2013-2014 (IBB) and PEST-C/EQB/LA0006/2011 (REQUIMTE). Manuela D. Machado gratefully acknowledges the postdoctoral (SFRH/BPD/72816/2010) grant from FCT.

\section{References}

1. Schmidt, C. K., Fleig, M., Sacher, F., \& Brauch, H. E. (2004). Environmental Pollution, 131, 107-124.

2. Knepper, T. P. (2003). Trac-Trends Anal. Chemical, 22, 708-724.

3. Nowack, B. and VanBriesen, J.M. (2005) Biogeochemistry of chelating agents, vol. 910. Nowack, B. and VanBriesen, J.M., (eds.). Washington DC: American Chemical Society, pp. 1-18

4. Bucheli-Witschel, M., \& Egli, T. (2001). FEMS Microbiol. Review, 25, 69-106.

5. Hider, R. C., \& Kong, X. L. (2010). Natural Product Reports, 27, 637-657.

6. Budzikiewicz, H. (2010) Iron uptake and homeostasis in microorganisms. Cornelis, P. and Andrews, S.C., (eds.). Wymondham: Caister Academic Press, pp. 1-16

7. Carrano, C. J., Drechsel, H., Kaiser, D., Jung, G., Matzanke, B., Winkelmann, G., Rochel, N., \& AlbrechtGary, A. M. (1996). Inorganic Chemistry, 35, 6429-6436.

8. von Wiren, N., Khodr, H., \& Hider, R. C. (2000). Plant Physiology, 124, 1149-1157.

9. Martell, A.E. and Smith, R.M. (2004) Standard reference database 46 version 8.0. New York: National Institute of Standards and Technology (NIST), US Department of Commerce

10. Warren, R. A. J., \& Neilands, J. B. (1965). The Journal of Biological Chemistry, 240, 2055-2058.

11. Pierwola, A., Krupinski, T., Zalupski, P., Chiarelli, M., \& Castignetti, D. (2004). Applied and Environmental Microbiology, 70, 831-836.

12. Winkelmann, G., Busch, B., Hartmann, A., Kirchhof, G., Sussmuth, R., \& Jung, G. (1999). Biometals, 12 , 255-264.

13. Yehuda, Z., Shenker, M., Hadar, Y., \& Chen, Y. N. (2000). Journal of Plant Nutrition, 23, 1991-2006.

14. Das, A., Prasad, R., Srivastava, A., Giang, P.H., Bhatnagar, K. and Varma, A. (2007) Microbial siderophores. Varma, A. and Chincholkar, S.B. (eds.). Berlin: Springer, pp. 1-42

15. Nagoba, B., \& Vedpathak, D. (2011). European of Journal General Medicine, 8, 229-235.

16. Miller, M. J. (1989). Chemical Reviews, 89, 1563-1579.

17. Shenker, M., \& Chen, Y. (2005). Soil Science \& Plant Nutrition, 51, 1-17.

18. Lankford, C. E., Walker, J. R., Reeves, J. B., Nabbut, N. H., Byers, B. R., \& Jones, R. J. (1966). Journal of Bacteriology, 91, 1070-1079.

19. Arceneaux, J., Davis, W. B., Downer, D. N., Haydon, A. H., \& Byers, B. R. (1973). Journal of Bacteriology, 115, 919-927.

20. Arceneaux, J. E. L., \& Byers, B. R. (1976). Journal of Bacteriology, 127, 1324-1330. 
21. Arceneaux, J. E. L., \& Byers, B. R. (1980). Journal of Bacteriology, 141, 715-721.

22. Hu, X. C., \& Boyer, G. L. (1995). Biometals, 8, 357-364.

23. Mullis, K. B., Pollack, J. R., \& Neilands, J. B. (1971). Biochemistry, 10, 4894-4898.

24. Gaballa, A. and Helmann, J.D. (2010) Iron uptake and homeostasis in microorganisms. Cornelis, P. and Andrews, S.C., (eds.). Wymondham: Caister Academic Press, pp. 229-246.

25. Hu, X. C., \& Boyer, G. L. (1996). Applied and Environmental Microbiology, 62, 4044-4048.

26. Davis, W. B., McCauley, M. J., \& Byers, B. R. (1971). Journal of Bacteriology, 105, 589-594.

27. Byers, B. R., Powell, M. V., \& Lankford, C. E. (1967). Journal of Bacteriology, 93, 286-294.

28. Storey, E. P., Boghozian, R., Little, J. L., Lowman, D. W., \& Chakraborty, R. (2006). Biometals, 19, 637-649.

29. Nicolaisen, K., Moslavac, S., Samborski, A., Valdebenito, M., Hantke, K., Maldener, I., Muro-Pastor, A. M., Flores, E., \& Schleiff, E. (2008). Journal of Bacteriology, 190, 7500-7507.

30. Sonier, M. B., Contreras, D. A., Treble, R. G., \& Weger, H. G. (2012). Botany-Botanique, 90, 181-190.

31. Alexander, D. B., \& Zuberer, D. A. (1991). Biology and Fertility of Soils, 12, 39-45.

32. Schwyn, B., \& Neilands, J. B. (1987). Analytical Biochemistry, 160, 47-56.

33. Chaplin, M.F. (1986) Carbohydrate analysis - a practical approach. Chaplin, M.F. and Kennedy, J.F. (eds.). Washington DC: IRL Press. pp. 1-36

34. Schalk, I. J., Hannauer, M., \& Braud, A. (2011). Environmental Microbiology, 13, 2844-2854.

35. Villegas, M.E.D. (2007) Microbial siderophores, vol. 12. Varma, A. and Chincholkar, S.B. (eds.). Berlin: Springer. pp. 219-231

36. Vary, P. S., Biedendieck, R., Fuerch, T., Meinhardt, F., Rohde, M., Deckwer, W. D., \& Jahn, D. (2007). Applied Microbiology and Biotechnology, 76, 957-967.

37. Schaeffer, P. (1969). Bacteriological Reviews, 33, 48-71.

38. Schallmey, M., Singh, A., \& Ward, O. P. (2004). Canadian Journal of Microbiology, 50, 1-17.

39. Martin, J. F., \& Demain, A. L. (1980). Microbiological Reviews, 44, 230-251.

40. Ruiz, B., Chavez, A., Forero, A., Garcia-Huante, Y., Romero, A., Sanchez, M., Rocha, D., Sanchez, B., Rodriguez-Sanoja, R., Sanchez, S., \& Langley, E. (2010). Critical Reviews in Microbiology, 36, 146-167.

41. Tschierske, M., Drechsel, H., Jung, G., \& Zahner, H. (1996). Applied Microbiology and Biotechnology, 45, 664-670.

42. Wilson, M. K., Abergel, R. J., Arceneaux, J. E. L., Raymond, K. N., \& Byers, B. R. (2010). Biometals, 23 , 129-134.

43. Chincholkar, S.B., Chaudhari, B.L. and Rane, M.R. (2007) Microbial siderophores, vol. 12. Varma, A. and Chincholkar, S.B. (eds.). Berlin: Springer, pp. 233-242

44. Duffy, B. K., \& Defago, G. (1999). Applied and Environmental Microbiology, 65, 2429-2438.

45. Stulke, J., \& Hillen, W. (2000). Annual Review of Microbiology, 54, 849-880.

46. Gupta, N., Mehra, G., \& Gupta, R. (2004). Canadian Journal of Microbiology, 50, 361-368.

47. Ayoub, M., \& Abdullah, A. Z. (2012). Renewable and Sustainable Energy Reviews, 16, 2671-2686.

48. Guimaraes, P. M. R., Teixeira, J. A., \& Domingues, L. (2010). Biotechnology Advances, 28, 375-384.

49. Chisti, Y. and Moo-Young, M. (2001) Basic biotechnology: 2nd ed. Ratledge, C. and Kristiansen, B. (eds.). Cambridge: Cambridge University Press. pp. 151-171 